\title{
Wound healing potential of Tillandsia recurvata and Guaiacum officinale in streptozotocin induced Type 1 Diabetic rats
}

\author{
Perceval Steven Bahado-Singh ${ }^{1,2,4,6}$, Cliff Kelvin Riley ${ }^{3,4}$, Henry Isaac Lowe ${ }^{4}$, \\ Charah Tabetha Watson ${ }^{4}$, Andrew O'Brien Wheatley ${ }^{1,2}$, Errol St. Aubyn York Morrison ${ }^{4,5}$ \\ ${ }^{1}$ Biotechnology Center, University of the West Indies, Mona Campus, Kingston, Jamaica \\ ${ }^{2}$ Department of Basic Medical Sciences (Biochemistry Section), University of the West Indies, Mona Campus, Kingston, Jamaica \\ ${ }^{3}$ College of Health Science, University of Technology, Kingston, Jamaica \\ ${ }^{4}$ Biotech R\&D Institute Ltd, Kingston, Jamaica \\ ${ }^{5}$ Office of the President, University of Technology, Kingston, Jamaica \\ ${ }^{6}$ Office of the Principal, University of West Indies, Mona Campus, Kingston, Jamaica
}

\author{
Email address: \\ Perceval.bahadosingh@gmail.com (P. S. Bahado-Singh)
}

\section{To cite this article:}

Perceval Steven Bahado-Singh, Cliff Kelvin Riley, Henry Isaac Lowe, Charah Tabetha Watson, Andrew O’Brien Wheatley, Errol St. Aubyn York Morrison. Wound Healing Potential of Tillandsia recurvata and Guaiacum officinale in Streptozotocin Induced Type 1 Diabetic Rats. American Journal of Biomedical and Life Sciences. Vol. 2, No. 6, 2014, pp. 146-149. doi: 10.11648/j.ajbls.20140206.12

\begin{abstract}
One of the major challenges faced by people living with diabetes is the treatment and management of diabetic sores and ulcers. Jamaican Ball Moss (Tillandsia recurvata sp.) and Lignum Vitae (Guaiacum officinale) are indigenous to the West Indian region and have been widely studied and used as ethnomedicinal remedies to treat numerous diseases. The anti-tumor properties of the Ball Moss has been the centre of recent discussions, however, both plants are quite popular among Jamaican folklore medicine as effective anti-inflammatory remedies in the treatment of arthritic and rheumatic conditions. This study evaluated the wound healing potential of Tillandsia recurvata sp. and Guaiacum officinale in an excision wound model of normal and streptozotocin induced type I diabetic rats. Rats were grouped $(n=6)$ with similar weight. Animals were placed into 7 study groups, each with different treatments administered topically. All animals were experimentally wounded on the posterior surface. Normal and diabetic groups were treated with Vaseline (control group), Lignum Vitae and Ball Moss extracts and Neosporin (standard group). Animals treated with Ball Moss showed a reduction by $56 \%$ (normal) and $52 \%$ (diabetic) in wound area while Lignum Vitae resulted in a $47 \%$ (normal rats) and $40.5 \%$ (diabetic rats) reduction. The wound area reduction was significantly higher than that of the control with $32 \%$ and $22 \%$ for normal and diabetic rats respectively. The results obtained indicated that both Ball Moss and Lignum Vitae possess wound healing properties with efficacy similar to that of Neosporin.
\end{abstract}

Keywords: Diabetes, Wound healing, Jamaican Ball Moss

\section{Introduction}

Wound healing is initiated after injury and involves elaborate biochemical processes resulting in the restoration of cellular structure and tissue layers [1]. Wound healing occurs as a cellular response to injury and involves activation of keratinocytes, fibroblasts, endothelial cells and macrophages. Platelets, regulated by thrombopoietin, play a pivotal role in the normal haemostasis response. This occurs sequentially, firstly by platelet adhesion followed by platelet activation and then platelet aggregation, which results in the formation of a primary haemostatic plug. Platelet stimulates wound healing through platelet-derived growth factor (PDGF). This growth factor is mitogenic for vascular smooth muscle cells and fibroblasts. The blood coagulation cascade is also pivotal in normal haemostasis response, particularly for the formation of a permanent haemostatic plug. This secondary tissue repair process involves the activation of a series of key clotting factors, including important enzymes such as thrombin and serine proteases. Numerous clotting factors are synthesised in the liver, some (II, VII, IX and X) are vitamin K dependent, as well as cytokines released by various cell types, are needed to 
coordinate and maintain healing [1].

Deterrents to the conventional wound healing process include various mechanical and physiological factors as well as systemic diseases. Diabetes mellitus is one such disease in which wound healing is often impaired due to a variety of connective tissue abnormalities. Connective tissue repair involves formation of a fibrous scar and synthesis of collagen, its major constituent. The synthesis, secretion and organization of collagen are extremely important as it is instrumental in providing strength and integrity to the dermis and supportive tissues $[2,3]$.

The underlying limitations of diabetic wound healing is unresolved and remains the focus of extensive research, though several studies have concluded deficiencies in various phases of the healing process. The increased frequency with which glycosylation occurs in diabetics allows for the extension of the inflammatory phase of the healing process due to its effect on neutrophil and macrophage phagocytosis of bacteria [4]. Additionally, the proliferative stage is prolonged as a consequence of erythrocytes becoming less pliable, thus are unable to effectively deliver oxygen to the wound for tissue metabolism and collagen synthesis [4].

Impaired wound healing in diabetics remains a severe problem in clinical practice as individuals suffering from the condition often become morbid and may be hospitalized for extended periods resulting in enormous health-care expenses [5]. The current methods used to treat chronic diabetic wounds posses major drawbacks, with associated undesirable side effects. As a result, the scientific community has placed emphasis on uncovering natural products that may be useful in the treating diabetic wounds. Significant focus has been placed on plants traditionally used to treat various ailments [2, $5,6]$. Aqueous leaf extracts of Tribulus terrestris were found to possess wound healing activity in rats [5]. Additionally, Chithra et al. [2] reported that treatment of wounds in diabetic induced rats with Aloe vera enhanced the process of wound healing by influencing phases such as inflammation, fibroplasia, collagen synthesis and maturation as well as wound contraction. Similarly, ethanol extracts of Vinca rosea and Tribulus terrestris were reported to promote wound healing and closure in diabetic rats $[6,7]$.

Lignum Vitae is a slow growing tree with distinct bluish-purple flowers. The tree is commonly referred to as 'the tree of life' as it is believed to possess numerous medicinal properties. The resin of Lignum Vitae has been used to treat a host of medical conditions such as arthritis, gout and syphilis [8]. Ball Moss commonly referred to as "Old Man's Beard" is an epiphytic Bromeliad indigenous to Jamaica. The plant was found to have therapeutic and pharmacological activity as extracts from the plant exhibited anti-inflammatory and anti-tumor activities [9].

The identification of compounds capable of enhancing wound healing would have a positive impact on individuals suffering from diabetes and other conditions known to induce impaired wound healing. Currently, limited scientific evidence is available to establish whether or not Guaiacum officinale and Tillandsia recurvata possess wound healing potential despite widespread use in folklore medicinal practices.

\section{Materials and Methods}

\subsection{Collection of Plant Materials}

Lignum Vitae (Guaiacum officinale) and the Jamaican Ball Moss (Tillandsia recurvata) were collected and verified at the University of the West Indies, Mona herbarium.

\subsection{Preparation of Plant Extracts}

Freshly harvested Ball Moss plants and Lignum Vitae leaves $(100 \mathrm{~g})$ were washed with water, then milled in $200 \mathrm{~mL}$ of absolute ethanol using a Waring laboratory blender. The mixtures were allowed to stand in glass beakers for 24 hours at room temperature, followed by filtration and vaporisation of ethanol by means of a Buchi rotor evaporator. Ethanol was completely removed and animals treated with the remaining extract (paste) at a concentration of $100 \mathrm{mg} / \mathrm{Kg}$ body weight.

\subsection{Experimental Design}

Forty two (42) six-eight week old male adult Sprague-Dawley rats were obtained from the University of the West Indies, Mona Animal house after receiving ethical approval. The animals were separated and grouped by weight, labeled and placed into seven experimental groups. The average body weight of the rats was $254.5 \mathrm{~g}$. The animals were fed normal food and water ad libitum and housed in stainless steel cages that were maintained daily. Ketamine anesthesia ( $18 \mathrm{mg} / \mathrm{kg}$ body weight of an animal) was administered prior to and during infliction of the experimental wounds. Animals were monitored closely and those that showed signs of infection were excluded, separated and replaced in the study. Table 1 shows the control and experimental groups.

\subsection{Induction of Diabetes}

Type 1 Diabetes was induced in animals of groups 4, 5, and 6 by administering a dose of streptozotocin (STZ, $65 \mathrm{mg} / \mathrm{kg}$ ) in cold saline buffer, $\mathrm{pH} 4.5$ intravenously in the abdomen, after the weight and fasting blood glucose of the animals were determined. The average blood glucose before diabetes induction was found to be $3.6 \mathrm{mmol} / \mathrm{L}$ or $64.8 \mathrm{mg}$ $\mathrm{d} / \mathrm{L}$ and was measured one week later to ensure induction was effective. Animals with blood glucose levels $\geq 8.3$ $\mathrm{mmol} / \mathrm{L}$ or $\geq 150 \mathrm{mg} \mathrm{d} / \mathrm{L}$ were considered diabetic. A Tru Result glucometer was used to measure blood glucose with blood obtained from the tail vein.

\subsection{Excision Wound Creation}

All animals were anesthetised using $1.5 \mathrm{~mL}$ of intravenous ketamine hydrochloride $(18 \mathrm{mg} / \mathrm{Kg}$ body weight). An area on the right posterior region of each rat was then carefully shaved and outlined using a marker and stencil to delineate the area where the wound was created. An excision wound $1.5 \mathrm{~cm}$ in length and $0.2 \mathrm{~cm}$ in depth was then created along the 
outline using toothed forceps, surgical blade and pointed scissors as outlined by Nayak [6].

\subsection{Wound Treatment and Measurement}

Animals in groups 2 and 5 were each treated topically with Ball Moss plant extract ( $100 \mathrm{mg} / \mathrm{kg}$ body weight), applied at a single layer thickness to the wound daily for 12 days. Similarly, animals in groups 3 and 6 were treated with Lignum Vitae extract; groups 1 and 4 were treated with Vaseline (control); and group 7 with Neosporin (positive control). The wound areas were measured for all groups at baseline and on days 2, 4, 6, 8, 10 and 12 using transparency sheet and permanent markers. The wound area were recorded and measured on graph paper.

Table 1. Animal groups and treatment modalities

\begin{tabular}{lll}
\hline Group & Group Description & Experimental Treatment \\
\hline 1 & Normal Control & Vaseline \\
2 & Normal Experimental & Ball Moss extract \\
3 & Normal Experimental & Lignum Vitae extract \\
4 & Diabetic Control & Vaseline \\
5 & Diabetic Experimental & Ball Moss extract \\
6 & Diabetic Experimental & Lignum Vitae extract \\
7 & Standard & Neosporin \\
\hline
\end{tabular}

\subsection{Statistical Analysis}

The results were expressed as mean \pm Standard Error of the Mean (SEM). One-way analysis of variance (ANOVA) was used to assess the differences between groups. Data was analysed using the statistical package for Statistical Software version 19 (SPSS) and values with $\mathrm{p}<0.05$ were considered statistically significant.

\section{Results and Discussion}

The results indicated that wound reduction was significantly improved in the diabetic experimental animals (groups 5 and 6) treated with Ball Moss and Lignum Vitae topical preparations, when compared to the normal and diabetic controls (groups 1 and 4 respectively). The average wound diameter for the diabetic experimental animals after 12 days of treatment were $0.72 \pm 0.247 \mathrm{~cm}$ and $0.80 \pm 0.044 \mathrm{~cm}$ for Ball Moss and Lignum Vitae extracts respectively compared to $1.16 \pm 0.046 \mathrm{~cm}$ and $1.02 \pm 0.048 \mathrm{~cm}$ for diabetic and normal controls respectively (Table 2). The wound healing property of Ball Moss in diabetic animals was comparable to that of Neosporin. However, the Ball Moss preparation proved to be more efficacious than Neosporin when used in normal animals $(0.065 \pm 0.02$ compared to 0.70 \pm 0.03 ). These results suggest that the Ball Moss extract was significantly more effective in accelerating the wound healing process than that of Lignum Vitae and Neosporin ointment $(p<0.05)$. Animals which were not treated with Ball Moss, Lignum Vitae extracts or Neosporin ointment showed slow wound healing, with values of $32 \%$ for normal and $22.67 \%$ for diabetic animals after 12 days. A significant reduction in wound size in the diabetic groups was observed as early as 6 days after treatment (14.67\% for Ball Moss and $10.67 \%$ for Lignum Vitae). An overall reduction of $52 \%$ and $46.67 \%$ was observed for diabetic animals treated with Ball Moss and Lignum Vitae respectively, after 12 days of treatment. Contraction of the wound was most effective in animals treated with Neosporin ointment and Ball Moss preparation. Singer and Clarke [9] reported that diabetic wounds are slow, non-healing wounds that can last for several weeks, despite adequate and appropriate care. As such, clinical management of the wounds is very challenging. The exact pathogenesis of poor wound healing in diabetics is not clearly understood, however, studies have revealed abnormalities in the various phases of wound healing $[10,11]$. Some of the most common abnormalities reported include, impaired blood flow and oxygen release from increased blood sugar, impaired local immune and cell defenses, decreased anabolic activity with decreased insulin and growth hormone and drainage of fluids due to deficiencies in the vascular and lymphatic systems in diabetic wounds, resulting in tissue and cellular death [12]. Neutrophil functions such as chemotaxis, migration, bactericidal and phagocytic activity are also affected by hyperglycaemia [12].

Ball Moss and Lignum Vitae extracts may have influenced the wound healing process by increasing blood supply, thereby increasing oxygen supply to the wound and blocking Vasoconstrictive compounds; increase migration of epidermal cells and extensive reorientation of collagen fibers caused by a stronger cross-linking [6, 13]. Similar results of wound healing properties were reported for Aloe vera [14], Carica papaya [15] and Catharanthus roseus [16]. The presence of Vasoconstrictive compounds in Lignum Vitae such as guaiaretic and guaiaconic acids may have had a direct effect on wound contraction and increased rate of epithelialisation. Also, stronger cross-linking may have been effected leading to increased epithelial cell migration, readjustment of collagen fibers and thus improved tissue healing. Additionally, the extracts seemingly reduced the amount of dead tissue at wound sites thus enhancing wound healing. Collagen synthesis, inflammation, maturation and wound contraction may have been affected due to the reported hypoglycaemic effects of these plants. The wound healing activity of the extracts studied could also be as a result of the antioxidant activity of the phytochemicals present, thus eliciting a free radical scavenging action. Ahmad et al [17] reported the presence of saponins in Lignum Vitae which are known to elicit antioxidant activity. In addition to this, the antimicrobial activity of the plant extracts could have aided in the increased wound healing properties observed. The result obtained could also be a function of either individual or synergistic effects of bioactive molecules present in the extracts.

However, research is needed, to include isolation and characterisation of individual compounds in Ball Moss and Lignum Vitae extracts, in order to identify the mechanism of action, in the wound healing process. Identification of these compounds could lead to the development of novel therapeutic agents for the diabetic wound treatment. 
Table 2. Wound healing activity of the Ball Moss and Lignum Vitae in normal and streptozotocin induced type 1 diabetic rats

\begin{tabular}{|c|c|c|c|c|c|c|c|}
\hline \multirow[b]{2}{*}{ Days } & \multicolumn{7}{|c|}{ Wound diameter after treatment $(\mathrm{cm})$} \\
\hline & $\begin{array}{l}\text { Vaseline } \\
\text { (normal } \\
\text { control) }\end{array}$ & $\begin{array}{c}\text { Ball Moss } \\
\text { extract (normal) }\end{array}$ & $\begin{array}{c}\text { Lignum Vitae } \\
\text { extract (normal) }\end{array}$ & $\begin{array}{l}\text { Vaseline extract } \\
\text { (Diabetic control) }\end{array}$ & $\begin{array}{c}\text { Ball Moss extract } \\
\text { (diabetic) }\end{array}$ & $\begin{array}{c}\text { Lignum Vitae } \\
\text { extract (Diabetic) }\end{array}$ & Neosporin \\
\hline $1 \& 2$ & $1.50 \pm 0^{\mathrm{e}}$ & $1.50 \pm 0^{\mathrm{f}}$ & $1.50 \pm 0^{\mathrm{e}}$ & $1.50 \pm 0^{\mathrm{e}}$ & $1.50 \pm 0^{\mathrm{f}}$ & $1.50 \pm 0^{\mathrm{e}}$ & $1.50 \pm 0^{\mathrm{f}}$ \\
\hline 4 & $1.47 \pm 0.02^{\mathrm{d}}$ & $1.37 \pm 0.307^{\mathrm{e}}$ & $1.39 \pm 0.015^{\mathrm{d}}$ & $1.43 \pm 0.017^{\mathrm{d}}$ & $1.38 \pm 0.029^{\mathrm{e}}$ & $1.39 \pm 0.016^{\mathrm{d}}$ & $1.43 \pm 0.028^{\mathrm{e}}$ \\
\hline 6 & $1.42 \pm 0.017^{\mathrm{d}}$ & $1.28 \pm 0.046^{\mathrm{d}}$ & $1.30 \pm 0.022^{\mathrm{c}}$ & $1.41 \pm 0.015^{\mathrm{d}}$ & $1.28 \pm 0.024^{\mathrm{d}}$ & $1.34 \pm 0.214^{\mathrm{c}}$ & $1.23 \pm 0.033^{\mathrm{d}}$ \\
\hline 8 & $1.33 \pm 0.028^{\mathrm{c}}$ & $1.01 \pm 0.327^{\mathrm{c}}$ & $1.28 \pm 0.021^{\mathrm{c}}$ & $1.37 \pm 0.019^{c}$ & $1.08 \pm 0.029^{c}$ & $1.31 \pm 0.015^{\mathrm{c}}$ & $1.11 \pm 0.035^{\mathrm{c}}$ \\
\hline 12 & $1.02 \pm 0.048^{\mathrm{a}}$ & $0.65 \pm 0.022^{\mathrm{a}}$ & $0.79 \pm 0.03^{\mathrm{a}}$ & $1.16 \pm 0.046^{\mathrm{a}}$ & $0.72 \pm 0.247^{\mathrm{a}}$ & $0.80 \pm 0.044^{\mathrm{a}}$ & $0.7 \pm 0.028^{a}$ \\
\hline
\end{tabular}

Values are mean \pm SEM. Values in columns with similar superscript letters are not significantly different $(\mathrm{p}<0.05)$.

\section{Conclusion}

This study demonstrates that topical administration of Ball Moss and Lignum Vitae ethanol extracts, at a concentration of $100 \mathrm{mg} / \mathrm{kg}$ body weight, may be used to accelerate the wound healing process in persons with diabetes. Ball Moss was found to be more effective than Lignum Vitae ethanolic extracts and Neosporin in accelerating wound healing. However, further studies are required to elucidate the mechanism of actions of the extracts as well as to include toxicity, histological and biochemical analysis of the wound healing process. Furthermore, randomised double blind clinical trials should be undertaken to validate efficacy and to ensure health safety. This should be done prior to the any recommendations for use by persons with diabetes or any other disease.

\section{Acknowledgments}

The authors would like to express sincere thanks to the Bio-Tech R\&D Institute, Jamaica, the Environmental Health Foundation of Jamaica and the Biotechnology Center, University of the West Indies, Mona Campus for funding this study.

\section{Disclosure}

The authors declare that they have no competing financial or non-financial interests. There are absolutely no conflicts of interest among the authors or any potential conflicts. PSB, and AOW conceptualised and designed the study. PSB and CKR collected the data, analysed and interpreted the data and prepared the manuscript. HICL and EYM provided technical oversight on the project, revised and critiqued the manuscript and data set. CTW contributed towards the preparation of the manuscript and data analyses.

\section{References}

[1] Brem H, Tomic-Canic M. Cellular and molecular basis of wound healing in diabetes. J Clin Invest 2007, pp. 1219-1222.

[2] Chithra P, Sajithlal GB, Chandrakasan G. Influence of Aloe vera on the healing of dermal wounds in diabetic rats. Journal of Ethnopharmacology 1998, pp.195-201.
[3] Al Bayaty F, Abdulla M, Abu Hassan MI, Masud M. Wound healing potential by hyaluronate gel in streptozotocin-induced diabetic rats. Scientific Research and Essays 2010, pp. 2756-2760.

[4] Rosenberg LZ, de la Torre J. Wound healing, growth factors. [http://www.emedicine.com/plastic/TOPIC457.HTM]. (2006).

[5] Velander P, Theopold C, Hirsch T, Bleiziffer O, Zuhaili B, Fossum M, et al. Impaired wound healing in an acute diabetic pig model and the effects of local hyperglycemia. Wound Repair Regeneration 2008, pp. 288-293.

[6] Nayak S. Influence of Ethanol Extract of Vinca rosea on Wound Healing in Diabetic Rats. Journal of Biological Sciences 2006, pp. 51-55.

[7] Wesley J, Christina AJM, Chidambaranathan N, Ravikumar K. Wound healing activity of the leaves of Tribulus terrestris (linn) aqueous extract in rats. Journal of Pharmacy Research 2009, pp. 841-843.

[8] Zeitlin IJ, Duwiejua M, Fabiyi A, Gray AI. Antiinflammatory activity in extracts from Guaiacum officinale wood cuts. British Journal of Pharmacology 1994, pp. 180.

[9] Lowe H. Anti-tumor and anti-inflammatory extracts of plant biomass and their uses. United States Patent. Patent number: US20080145464 A1. 2008.

[10] Goodson WH, Hunt TK. Studies of wound healing in experimental diabetes mellitus. J Surg Res1977, pp. 221-27.

[11] Goodson WH, Hunt TK. Wound healing and the diabetic patient. Surg Gynecol Obstet1979, pp. 600-608.

[12] Reiser KM. Nonenzymatic glycation of collagen in aging and diabetes. Proc Soc Expl Biol Med 1998, pp. 23-37.

[13] Johnson A. Towards rapid tissue healing. Plastic Surgical Nursing 1984, pp. 39-40.

[14] Davis R. Inhibitory and stimulatory systems in Aloe vera. Aloe Today Winter, 1992.

[15] Azarkan M, EI Moussaoui A, Van Wuytswinkel D, Dehon G,Looze Y. Fractionation and purification of the enzymes stored in the latex of Carica papaya. Journal of Chromatography B. 2003, pp. 229-238.

[16] Nayak BS, Pereira LMP. Catharanthus roseus flower extract has wound-healing activity in Sprague Dawley rats, BMC Complementary and Alternative Medicine 2006, pp. 41.

[17] Ahmad VU, Perveen S, Bano S. Guaiacin A and B from the Leaves of Guaiacum officinale. Planta Medica 1989, pp. 307-308. 